\title{
Hyphal Anastomosis Reactions, rDNA-Internal Transcribed Spacer Sequences, and Virulence Levels Among Subsets of Rhizoctonia solani Anastomosis Group-2 (AG-2) and AG-BI
}

\author{
D. E. Carling, S. Kuninaga, and K. A. Brainard
}

First and third authors: University of Alaska-Fairbanks, 533 E. Fireweed, Palmer 99645; and second author: Health Sciences University of

Hokkaido, Ishikari-Tobetsu, Hokkaido, 061-0293, Japan.

Accepted for publication 17 September 2001.

\begin{abstract}
Carling, D. E., Kuninaga, S., and Brainard, K. A. 2002. Hyphal anastomosis reactions, rDNA-internal transcribed spacer sequences, and virulence levels among subsets of Rhizoctonia solani anastomosis group-2 (AG-2) and AG-BI. Phytopathology 92:43-50.

Hyphal anastomosis reactions, rDNA-internal transcribed spacer (ITS) sequences, and virulence of isolates representing Rhizoctonia solani AG$\mathrm{BI}$ and six subsets of anastomosis group (AG)-2 (-2-1, -2-2 IIIB, -2-2 IV, $-2-2$ LP, $-2-3$, and -2-4) were compared. AG-2-4 is a subset described for the first time in this report. Anastomosis reactions within AG-BI and the listed subsets of AG-2 were generally strong but, between subsets, ranged from strong to a very weak "bridging"-type reaction. Anastomosis reaction alone generally did not provide adequate evidence for placement of an isolate into a subset of AG-2. Anastomosis reactions between AG-BI and the original subsets of AG-2 (-2-1 and -2-2) are very strong; for this reason, we propose that it be included as a subset of AG-2 (designation

reactions with all other subsets of AG-2 and thus may be candidates for independent AG status. Grouping within AG-2 based on rDNA-ITS sequences was consistent with the abovementioned subsets. However, grouping based on virulence as measured herein does not conform to established grouping patterns within AG-2 and does not seem useful as a group-defining criterion. A broad range of damage was observed among members of the most virulent subsets (-2-1, -2-2 IIIB, -2-2 IV, and -2-4), whereas other subsets (-2 BI, -2-2 LP, and -2-3) were similar to one another in causing a minimal level of damage. Group-specific primer pairs for each of the seven subsets of AG-2 were designed based on the abovementioned rDNA-ITS sequences. Primer pairs proved dependable and subset specific in polymerase chain reaction amplifications of purified genomic DNA from 109 isolates of $R$. solani and two isolates of binucleate Rhizoctonia. These primers will provide a simple and useful method for subset-specific characterization within AG-2 if further critical evaluations confirm their specificity.
\end{abstract} AG-2 BI). Subsets -2-3 and -2-4 show very weak bridging-type anastomosis
Rhizoctonia solani Kühn, also known by the genus name Moniliopsis (20) (teleomorph Thanatephorus cucumeris (A. B. Frank) Donk), is a common and highly heterogeneous fungal species. Many of its isolates are plant parasites. From the heterogeneous mix of isolates that is $R$. solani, subspecific groups called anastomosis groups (AGs) have been created based on hyphal anastomosis reactions. A definition of anastomosis plus detailed descriptions of categories of anastomosis reactions have been published (3). Grouping by hyphal anastomosis reaction is a traditional way of subdividing $R$. solani and, to date, 14 AGs have been described $(3-5,23,24)$.

Use of the AG concept does bring similar isolates of $R$. solani together into groups that are more homogeneous than the species as a whole. However, many AGs, like $R$. solani itself, contain isolates that vary from one another in terms of virulence, colony morphology, and other characteristics. AG-1, -2, -3, -4, -6, -7, -8, and -9 all have subsets (the term subset is applied to subdivisions of AGs and subdivisions of subdivisions of AGs), identified on the basis of characteristics including morphology, virulence, host range, nutritional requirements, biochemical characteristics, molecular characteristics, and DNA sequence $(1,6,12,24,32,33)$. Subsets of an AG identified based on one or more of these criteria are not always identical to subsets identified based on other criteria. Therefore, recognition of the subsets of an AG and the membership of

Corresponding author: D. E. Carling; E-mail address: pfdec@uaa.alaska.edu

Publication no. P-2001-1114-02R

(C) 2002 The American Phytopathological Society each subset depends on the criterion or combination of criteria used for characterization.

Heterogeneity within AG-2 is indicated by its many subsets. The most commonly referenced subsets of AG-2 include -2-1 (23), -2-2 IIIB $(24,25,38),-2-2$ IV $(25,38),-2-2$ LP $(8)$, and -2-3 $(9,21)$. Liu and Sinclair (17) proposed another system in which AG-2 is divided into five subsets $(2 \mathrm{~A}, 2 \mathrm{~B}, 2 \mathrm{C}, 2 \mathrm{D}$, and $2 \mathrm{E})$ that, in all but one case (2E), probably parallel a previously mentioned subset. Although, in most cases, isolates of AG-2 routinely can be placed into one subset or another, newly collected isolates sometimes initially appear to share characteristics of multiple subsets $(13,22)$.

In this article, we present a review of relationships among selected isolates representing AG-BI and subsets of AG-2. We identified the need for this study based on (i) the existence of an increasing number of subsets of AG-2 and uncertainty about similarities and differences among them; (ii) occasional difficulty in placing newly collected isolates of AG-2 into one or another of its subsets; (iii) the need to compare, in a single study, several of the techniques currently being used to define subsets of $R$. solani AG-2; and (iv) differences of opinion regarding the separateness of AG-BI from AG-2 $(1,15)$.

For this study, we assembled a set of 37 isolates to represent AG-BI and each of the commonly referenced subsets of AG-2, plus AG-2-4, an as yet undescribed subset of AG-2. In selecting isolates, we sought to represent as many hosts and geographical areas as possible. Isolates of AG-2t $(31)$ and AG-Nt $(13,22)$ were included as representatives of AG-2-1 because both are recognized as members of that subset. Each of the 37 isolates is evaluated in terms of: (i) hyphal anastomosis reaction, because it is a traditional, reliable, and widely used method; (ii) sequence simi- 
larity of the rDNA-internal transcribed spacer (ITS) regions, because it is objective, reproducible, and increasingly used; and (iii) virulence on seedlings of four plant species, because many isolates of $R$. solani AG-2 are plant pathogens and much of the early subset identification was based on virulence and host range. As a final step, specific primer pairs for each of the seven subsets of AG-2 studied were designed and tested. Primer design was based on sequences of the rDNA-ITS region.

We hypothesized that AG-BI and all subsets of AG-2 would give a bridging or stronger anastomosis reaction with one another but that anastomosis reaction would not be a useful criterion for placing isolates into subsets of AG-2. Further, we expected that groupings based on rDNA-ITS sequence would conform to AG-2 subset identification based on earlier findings but that groupings based on virulence would not.

\section{MATERIALS AND METHODS}

Assembly of isolate collection. The 37 isolates used in anastomosis, sequencing, virulence, and primer design studies are listed in Table 1. This list was assembled from our existing collections, from collections of other researchers, or from depositories. Depositories from which we drew samples included: Ministry of Agriculture, Forestry and Fisheries, Japan (MAFF); American Type Culture Collection (ATCC); and Institute for Fermentation, Osaka, Japan (IFO). Along with the original 37, an additional 74 isolates were selected, with attention to maximizing geographic and host range diversity, and used to test specificity of the designed primer pairs. Among the 74 isolates were 18 AG-2-1, one AG-2 BI, 16 AG-2-2 IIIB, 18 AG-2-2 IV, four AG-2-3, three AG-
2-4, two binucleate Rhizoctonia, one $R$. solani of uncertain AG affinity, and one isolate each from AG-1, -3, -4, -5, -6, -7, -8, -9, $-10,-11$, and -12 . The complete list of isolates and reactions to subset-specific primers is available from D. E. Carling or S. Kuninaga upon request.

Hyphal anastomosis reactions. Observations of hyphal anastomosis reactions were made according to a modification of the method of Parmeter et al. (3,26). Individual anastomosis reactions between hyphae of confronted isolates were assigned to one of eight categories. Four of these categories have been defined in detail $(3,18)$. They are $\mathrm{C} 0, \mathrm{C} 1, \mathrm{C} 2$, and $\mathrm{C} 3$, where $\mathrm{C} 0$ is no reaction and $\mathrm{C} 3$ a self (clonal) anastomosis reaction. Cataloguing a reaction into $\mathrm{C} 1, \mathrm{C} 2$, or $\mathrm{C} 3$, by definition $(3,18)$, requires the presence of five or more of the anastomosis points characteristic of that category. Due to the continuum of reaction types observed among the many isolates included here, four additional categories were defined specifically for this study: $\mathrm{C} 1-=1$ to $4 \mathrm{C} 1$ points, $\mathrm{C} 1+=8$ or more $\mathrm{C} 1$ points, $\mathrm{C} 2-=1$ to $4 \mathrm{C} 2$ points, and $\mathrm{C} 2+=8$ or more $\mathrm{C} 2$ points. These four new categories use the existing definitions for $\mathrm{C} 1$ and $\mathrm{C} 2$ reactions $(3,18)$ and differ based only on the number of observed anastomosis points. Addition of these categories permitted a more precise articulation of differences between anastomosis reactions of each isolate pair and thus between subsets.

DNA isolation. Each isolate was grown in potato dextrose broth (Difco Laboratories, Detroit) for 4 days at $25^{\circ} \mathrm{C}$. Mycelial mats were harvested by filtration, blotted dry, lyophilized, ground to a fine powder, then stored at $-20^{\circ} \mathrm{C}$ prior to DNA isolation. Genomic DNA was extracted according to a modification of a previously described procedure (14). Mycelial powder was suspended

TABLE 1. Tester isolates of Rhizoctonia solani anastomosis group (AG)-2 and AG-BI used in this study

\begin{tabular}{|c|c|c|c|c|c|c|}
\hline $\mathrm{AG}$ & Subgroup & Isolate & Origin & Host & Collector or supplier ${ }^{\mathrm{a}}$ & Accession no. ${ }^{b}$ \\
\hline 2 & 1 & F56L & United States (Alaska) & Solanum tuberosum & D. E. Carling & $\mathrm{AB} 054844$ \\
\hline 2 & 1 & $\mathrm{R} 123$ & Japan (Aichi) & Raphanus sativus & S. Kuninaga & $\mathrm{AB} 054845$ \\
\hline 2 & 1 & PS-2 & Japan (Tokushima) & Pisum sativum & MAFF 305221 & $\mathrm{AB} 054846$ \\
\hline 2 & 1 & F48 & Australia & Soil & ATCC 44658 & $\mathrm{AB} 054847$ \\
\hline 2 & 1 & RHS-47 & USA (Georgia) & Arachis hypogeae & ATCC 96102 & AB054848 \\
\hline 2 & 1(ZG5) & $88-033$ & Australia & Hordeum vulgare & G. MacNish & AB054849 \\
\hline 2 & $1(2 t)$ & R002 & Netherlands & Tulipa gesneriana & J. H. M. Schneider & $\mathrm{AB} 054850$ \\
\hline 2 & $1(2 t)$ & R105 & Netherlands & Tulipa gesneriana & J. H. M. Schneider & $\mathrm{AB} 054851$ \\
\hline 2 & $1(2 t)$ & $\mathrm{R} 144$ & Netherlands & Tulipa gesneriana & J. H. M. Schneider & $\mathrm{AB} 054852$ \\
\hline 2 & $1(\mathrm{Nt})$ & RT-23 & Italy & Nicotiana tabacum & R. Nicoletti & $\mathrm{AB} 054853$ \\
\hline 2 & $\mathrm{BI}$ & TE2-4 & Japan (Hokkaido) & Soil & S. Kuninaga & $\mathrm{AB} 054873$ \\
\hline 2 & $\mathrm{BI}$ & AI1-4 & Japan (Hokkaido) & Soil & S. Kuninaga & AB054874 \\
\hline 2 & $\mathrm{BI}$ & SH1-2 & Japan (Hokkaido) & Soil & S. Kuninaga & $\mathrm{AB} 054875$ \\
\hline 2 & $\mathrm{BI}$ & SH1-3 & Japan (Hokkaido) & Soil & S. Kuninaga & $\mathrm{AB} 054876$ \\
\hline 2 & $\mathrm{BI}$ & SHC81 & Japan (Hokkaido) & Soil & S. Kuninaga & $\mathrm{AB} 054877$ \\
\hline 2 & 2 IIIB & $\mathrm{C}-96$ & Japan (Fukuoka) & Juncus effusus & MAFF 237429 & $\mathrm{AB} 054854$ \\
\hline 2 & 2 IIIB & $87-36-1$ & United States (N. Dakota) & Phaseolus vulgaris & C. Windels & $\mathrm{AB} 054855$ \\
\hline 2 & 2 IIIB & $88-40-1$ & United States (New York) & Beta vulgaris & C. Windels & $\mathrm{AB} 054856$ \\
\hline 2 & 2 IIIB & $89-21-4$ & United States (Georgia) & Zea mays & C. Windels & $\mathrm{AB} 054857$ \\
\hline 2 & 2 IIIB & $65-\mathrm{L}-2$ & United States (Illinois) & Glycine $\max$ & ATCC 66489 & $\mathrm{AB} 054858$ \\
\hline 2 & $2 \mathrm{IV}$ & $87-24-4 \mathrm{~A}$ & United States (Minnesota) & Beta vulgaris & C. Windels & $\mathrm{AB} 054859$ \\
\hline 2 & $2 \mathrm{IV}$ & $\mathrm{H} 13$ & Honduras & Phaseolus vulgaris & G. Godoy-Lutz & $\mathrm{AB} 054860$ \\
\hline 2 & $2 \mathrm{IV}$ & DR-G02 & Dominican Republic & Phaseolus vulgaris & G. Godoy-Lutz & $\mathrm{AB} 054861$ \\
\hline 2 & $2 \mathrm{IV}$ & $\mathrm{H}-3-77$ & United States (Minnesota) & Daucus carota & ATCC 44659 & AB054862 \\
\hline 2 & $2 \mathrm{IV}$ & R9 & United States (Colorado) & Beta vulgaris & L. Pinella & $\mathrm{AB} 054863$ \\
\hline 2 & $2 \mathrm{IV}$ & W-22 & United States (Wisconsin) & Phaseolus vulgaris & ATCC 18619 & AB054864 \\
\hline 2 & $2 \mathrm{IV}$ & RI-64 & Japan (Ibaraki) & Beta vulgaris & ATCC 76125 & $\mathrm{AB} 054865$ \\
\hline 2 & $2 \mathrm{LP}$ & $48 \mathrm{R}$ & Japan (Hyogo) & Zoysia tenuifolia & M. Hyakumachi & $\mathrm{AB} 054866$ \\
\hline 2 & $2 \mathrm{LP}$ & G4 & Japan (Gifu) & Zoysia tenuifolia & M. Hyakumachi & AB054867 \\
\hline 2 & $2 \mathrm{LP}$ & G8 & Japan (Gifu) & Zoysia tenuifolia & M. Hyakumachi & $\mathrm{AB} 054868$ \\
\hline 2 & $2 \mathrm{LP}$ & RGR38 & Japan (Shizuoka) & Cynodon dactylon & M. Hyakumachi & AB054869 \\
\hline 2 & 3 & H5-307 & Japan (Miyagi) & Glycine $\max$ & MAFF 237258 & $\mathrm{AB} 054870$ \\
\hline 2 & 3 & H17-4 & Japan (Iwate) & Glycine $\max$ & S. Naito & $\mathrm{AB} 054871$ \\
\hline 2 & 3 & LB17-3-2 & Japan (Iwate) & Glycine $\max$ & S. Naito & $\mathrm{AB} 054872$ \\
\hline 2 & 4 & 221 & United States (Georgia) & Zea mays & R. Jones & $\mathrm{AB} 054878$ \\
\hline 2 & 4 & $758 \mathrm{C}$ & United States (Georgia) & Daucus carota & D. Sumner & AB054879 \\
\hline 2 & 4 & 777R1P5 SL2 & United States (Georgia) & Daucus carota & D. Sumner & $\mathrm{AB} 054880$ \\
\hline
\end{tabular}

a MAFF = Ministry of Agriculture, Forestry and Fisheries, Japan; and ATCC = American Type Culture Collection.

${ }^{\mathrm{b}}$ DNA Data Bank of Japan (DDBJ), Shizuoko, Japan. 
in NTE buffer (100 mM NaCl, $30 \mathrm{mM}$ Tris-HCl, $10 \mathrm{mM}$ EDTA, $10 \mathrm{mM}$ 2-mercaptoethanol, $\mathrm{pH}$ 8.0) containing $0.5 \%$ ( $\mathrm{vol} / \mathrm{vol}$ ) Nonidet P-40 and centrifuged at 10,000 rpm for $1 \mathrm{~min}$. The pellet was resuspended in NSE $(100 \mathrm{mM} \mathrm{NaCl}, 200 \mathrm{mM}$ sucrose, $10 \mathrm{mM}$ EDTA, pH 4.4) before adding TES buffer (10 mM Tris$\mathrm{HCl}, 250 \mathrm{mM}$ EDTA, $\mathrm{pH} 9.2$, and $2.5 \%$ sodium dodecyl sulfate). The homogenate was incubated for $30 \mathrm{~min}$ at $55^{\circ} \mathrm{C}$. The solution was extracted with an equal volume of phenol/chloroform/isoamyl alcohol (50:48:2) and centrifuged at 10,000 rpm for $20 \mathrm{~min}$. The upper layer was mixed with 0.1 volume of $3 \mathrm{M}$ sodium acetate, then with 0.54 volume of isopropanol. The DNA pellet was collected, rinsed with $70 \%$ ethanol, and dried under vacuum.

rDNA sequencing. The regions of rDNA that repeat from the $3^{\prime}$ end of the $18 \mathrm{~S}$ gene to the $5^{\prime}$ end of the $28 \mathrm{~S}$ gene were amplified using six primers: ITS2, 3, 4, and 5; NS 7 (39); and LR3 (27). Each polymerase chain reaction (PCR) primer was linked to the Rhodamine-labeled primers RV-M and M4 (TaKaRa, Ltd., Shiga Prefecture, Japan) for cycle sequencing reactions. The PCR amplification reactions were performed in a 50- $\mu 1$ mixture containing $50 \mathrm{mM} \mathrm{KCl}, 20 \mathrm{mM}$ Tris- $\mathrm{HCl}$ (pH 8.4), $1.5 \mathrm{mM} \mathrm{MgCl}, 200 \mu \mathrm{l}$ of each of the four deoxynucleoside triphosphates, 5 pmol of each primer, $1.0 \mu \mathrm{l}$ of template, and 2.5 units of Taq polymerase. The amplification was performed with a thermal cycler MP (TaKaRa, Ltd.). The cycle parameters were an initial denaturation at $94^{\circ} \mathrm{C}$ for $2 \mathrm{~min}$, followed by 30 cycles of denaturation at $94^{\circ} \mathrm{C}$ for $40 \mathrm{~s}$, annealing at $55^{\circ} \mathrm{C}$ for $1 \mathrm{~min}$, extension at $72^{\circ} \mathrm{C}$ for $1 \mathrm{~min}$, and a final extension at $72^{\circ} \mathrm{C}$ for $5 \mathrm{~min}$. A single-stranded (ss)DNA template was prepared using a previously described procedure (37). One of the PCR primers was biotinylated; the biotinylated PCR products were immobilized on streptavidin-coated paramagnetic beads (Dynabeads M-280 streptavidin, DYNAL, Oslo, Norway) and ssDNA was prepared according to the manufacturer's instructions. Both strands were then sequenced directly by cycle sequencing using a Thermo Sequenase premixed cycle sequencing kit (Amersham Life Science, Buckinghamshire, UK) and the Rhodamine-labeled primers described previously. The sequencing products were separated in $6 \%$ polyacrylamide gel and the fragments were monitored using a HITACHI DNA sequencer SQ5500E (Hitachi, Ltd., Tokyo).

Sequence analysis. The sequence data were checked between complementary strands and the resulting sequences were aligned using the computer software package CLUSTAL V (7). The alignment of all sequences was checked visually. DNA sequence similarity based on the proportion of different nucleotide sites, including insertion-deletion, was calculated from the data using the Lipman-Peason algorithm (16) in the DNASIS software package (Hitachi). A tree showing the phylogenetic relatedness between isolates was constructed from distance matrix values by the neighbor-joining method (28) using the computer software package CLUSTAL V (7). Distances in the ITS-5.8S rDNA region were determined by Kimura's two-parameter model (10), omitting all sites with gaps. A bootstrap analysis using 1,000 resamples of the sequence data was carried out.

Development of group specific primers. Primer pairs specific to each of the seven subgroups included in Table 1 were designed (Hitachi Software Engineering Co., Yokohama, Japan). Also, primers specific to AG-2-2, that is, reactive with all three subgroups of AG-2-2 (IIIB, IV, and LP), were designed. Primer specificity was based on sequence differences in the ITS1 and ITS2 regions, and isolate sequences used for these comparisons are those listed in Table 1. Specific primers were synthesized by Hokkaido System Sciences, Ltd. (Sapporo, Hokkaido, Japan). PCR reactions were conducted as described above except for differences in annealing temperatures for each primer pair. Reaction products were separated on agarose gels, stained with ethidium bromide, then viewed using a UV transilluminator.

Virulence determination. Virulence of the 37 isolates was determined on radish (Raphanus sativus L., cv. Fancy Red), cauli- flower (Brassica oleracea L. var. botrytis L., cv. Imperial 10-6), romaine lettuce (Lactuca sativa L. var. longifolia Lam., cv. Green Towers), and sugar beet (Beta vulgaris L., cv. Auris). Damage assessments were determined on germinating seeds on $2 \%$ water agar in 100-by-15-mm petri dishes. Each dish was seeded in the center with a 7-mm-diameter potato dextrose agar (PDA) disk of the appropriate fungal isolate. Sterile PDA disks were used to seed the control treatments. Two days after seeding petri dishes with the various fungus treatments, 18 surface-sterilized $(0.3 \% \mathrm{NaOCl}$ for $3 \mathrm{~min}$ ) seeds (six seeds per dish) were evenly spaced on the agar surface in a circle halfway between the center and the edge of the dish. The growing fungal colonies reached the seeds just as they began to germinate. Stacks of dishes were placed in plastic boxes in a growth chamber in the dark at $21^{\circ} \mathrm{C}$. Notes on damage to developing seedlings were taken at 3 and 8 days after placement of the seeds on the agar. Damage assessment levels included $0=$ no damage; $1=$ minor discoloration of hypocotyl; 2 = discoloration plus small $(<1$-mm-diameter) necrotic lesions on stem, hypocotyl, or root; $3=$ discoloration plus large ( $\geq 1$-mm-diameter) necrotic lesions on stem, hypocotyl or root; and $4=$ seedling dead. All experiments designed to determine virulence were repeated once.

\section{RESULTS}

Hyphal anastomosis reactions. Hyphal anastomosis reactions observed between all combinations of confronted pairs of the 37 isolates are presented in Figure 1. All eight categories enumerated earlier $(\mathrm{C} 3, \mathrm{C} 2+, \mathrm{C} 2, \mathrm{C} 2-, \mathrm{C} 1+, \mathrm{C} 1, \mathrm{C} 1-$, and $\mathrm{C}$, listed from the least distant to the most distant relationship) are included. Anastomosis was judged to have occurred if a reading of $\mathrm{C} 1-$ or higher was observed.

All 37 isolates, when paired with themselves, gave the expected $\mathrm{C} 3$ or clonal anastomosis reaction. When isolates were paired with others from the same subset (i.e., $-2-1$ isolate $\times-2-1$ isolate), $93 \%$ gave the expected $\mathrm{C} 2$ or $\mathrm{C} 2+$ reaction. Anastomosis reactions between isolates representing different subsets of AG-2 indicate that subset relationships range from very close to distant. For example, all isolates of subset AG-2-1 anastomosed with all isolates of subset $-2 \mathrm{BI}, 26 \%$ with a strong reaction and $74 \%$ with a bridging reaction. Similarly, all isolates of subset -2-1 anastomosed with all isolates of subset -2-2 IIIB (14\% strong and $86 \%$ bridging). The majority of isolates of the other four subsets (-2-2 IV, -2-2 LP, -2-3, and -2-4) anastomosed with isolates of -2-1, although some pairings of each gave the $\mathrm{C} 0$ reaction, indicating a more distant relationship between these four subsets and -2-1.

Anastomosis reactions indicate that subset AG-2 BI is more closely related to subsets $-2-2$ IIIB and -2-2 IV than to -2-1. All isolates of -2-2 IIIB and -2-2 IV anastomosed with -2 BI, with strong reactions accounting for 80 and $40 \%$, respectively. Although most isolates of subsets -2-2 LP, -2-3, and -2-4 also anastomosed with $-2 \mathrm{BI}$, nearly all anastomoses were of the bridging type, and $20 \%$ of the $-2-3$ isolates gave the $\mathrm{C} 0$ reaction with $-2 \mathrm{BI}$.

All isolates of subset AG-2-2 IIIB anastomosed with all isolates of all other subsets except $-2-3$, where $27 \%$ gave the $\mathrm{C} 0$ reaction. More than $80 \%$ of subsets -2 BI, -2-2 IV, and -2-2 LP gave the strong reaction with -2-2 IIIB, indicating their close relationship with -2-2 IIIB. Also, all isolates of -2-4 reacted with all isolates of $-2-2$ IIIB but $100 \%$ were bridging reactions, illustrating a uniform but more distant relationship.

Subsets -2-3 and -2-4 differ from the other five subsets of AG-2 in that they do not show a strong affinity for each other or for the other five subsets. Although many -2-3 and -2-4 isolates bridge with each other and with isolates of other subsets, only one pairing gave the $\mathrm{C} 2$ reaction. Additionally, $67 \%$ of $-2-3$ and $-2-4$ isolates did not react at all $(\mathrm{C} 0)$ with each other.

rDNA sequence evaluation. Lengths of the ITS1 region within subsets varied by as many as 8 bp in AG-2-1 to none in -2-2 LP, 
$-2-3$, and $-2-4$. Similarly, length differences in ITS2 ranged from 8 bp in -2 BI to none in -2-2 IIIB, -2-2 LP, -2-3, and -2-4. Percentages of sequence similarity among all subsets of AG-2 range from 71 to $97 \%$ in ITS1 and from 81 to $98 \%$ in ITS2. Levels of similarity in ITS2 were high $(>90 \%)$ between $-2-1$ and all other subsets except -2 BI. At the same time, levels of similarity in ITS1 tended to be low between -2-1 and most other subsets. Also noteworthy is the high level of similarity (>90\%) among the three subsets (IIIB, IV, and LP) of -2-2 in ITS1 and ITS2.

A neighbor joining tree based on sequence differences in the ITS-5.8S rDNA region (Fig. 2) illustrates estimates of phylogenetic relationships among the seven subsets of AG-2. Subsets $-2-1,-2-3,-2-4$, and -2 BI are shown as separate groups, whereas the three subsets of -2-2 (IIIB, IV, and LP) form a cluster. AG-2-4 shows a relatively close relationship with $-2-1$.

Virulence determination. A summary of damage caused by the 37 isolates representing the seven subsets of AG-2 is presented in Table 2. Incidence and level of damage on radish and cauliflower was similar; therefore, data on radish are not included. Under the conditions of this study, which were highly favorable to the pathogen, nearly all isolates of all subsets caused minimal or greater levels of damage to all hosts. AG-2 BI, -2-3, and -2-2 LP, along with the AG-3 control, caused minimal damage to all four hosts, whereas -2-2 IIIB and -2-4, along with the AG-1 and AG-4 controls, severely damaged all four hosts. AG-2-1 and -2-2 IV also caused extensive damage, especially to radish and cauliflower. The AG-4 isolate killed all hosts by 8 days after inoculation, as did three isolates of -2-2 IIIB (65-L-2, 87-36-1, and C-96) and one isolate of -2-2 IV (R9). Of the 10 isolates of -2-1, 8 killed radish and cauliflower, as did 4 isolates of -2-2 IV. One isolate (88-40-1) of -2-2 IIIB and four isolates of -2-2 IV (DR-G02, W-22, 87-244A, and H-3-77) killed all hosts except lettuce by the 8-day reading. Of the four hosts, radish and cauliflower generally were most heavily damaged, and lettuce least damaged, by each subset. A notable exception was subset $-2-4$, which heavily damaged all four hosts but killed only lettuce.

\begin{tabular}{|c|c|c|c|c|c|c|c|c|c|c|c|c|c|c|c|c|c|c|c|c|c|c|c|c|c|c|c|c|c|c|c|c|c|c|c|c|c|}
\hline & \multicolumn{10}{|c|}{$A G-2-1$} & \multicolumn{5}{|c|}{$\mathrm{AG}-2 \mathrm{BI}$} & \multicolumn{5}{|c|}{ AG-2-2 IIIB } & \multicolumn{7}{|c|}{$\mathrm{AG}-2-2 \mathrm{IV}$} & \multicolumn{4}{|c|}{$A G-2-2$ LP } & \multicolumn{3}{|c|}{$A G-2-4$} & \multicolumn{3}{|c|}{$\mathrm{AG}-2-3$} \\
\hline & 㕝 & $\begin{array}{l}\hat{y} \\
\text { wh } \\
\frac{1}{\alpha}\end{array}$ & $\frac{d}{d x}$ & $\frac{7}{4}$ & 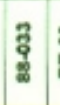 & $\underset{t}{2}$ & w & $\frac{j}{d x}$ & $\frac{8}{x}$ & 8 & ส & 㶾 & $\frac{7}{2}$ & $\frac{7}{\frac{7}{5}}$ & $\frac{2}{\frac{7}{5}}$ & 3 & 离 & § & $\frac{7}{\not{y}}$ & कै & $\begin{array}{l}8 \\
8 \\
\frac{\alpha}{\alpha}\end{array}$ & सุ & $\grave{c}$ & $\begin{array}{l}\frac{5}{J} \\
\text { वै } \\
\text { के }\end{array}$ & 点 & $\notin$ & $\frac{\$}{\bar{\alpha}}$ & 幽 & $\Xi$ & \$ & $\begin{array}{l}\frac{9}{3} \\
\frac{2}{g} \\
\frac{1}{x}\end{array}$ & 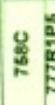 & $\frac{5}{E}$ & สู & 点 & 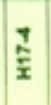 & $\begin{array}{l}z \\
\frac{7}{5} \\
\frac{5}{9}\end{array}$ \\
\hline FS6L & $\mathrm{ca}$ & $\mathrm{C}_{2}+\mathrm{C}$ & $\mathrm{C} 2+$ & $\mathrm{C} 2+$ & $\mathrm{C} 2+$ & $\mathrm{C} 2$ & $\mathrm{C} 2 \mathrm{C}$ & $\mathrm{C} 2+\mathrm{C}$ & $\mathrm{C} 2+\mathrm{C}$ & $\mathrm{C2}$ & C2. & C1 C & $\mathrm{Cl} \mathrm{C}$ & c2. & c1 & $\mathrm{C} 2$ & C2. & C1 & C2. & c1 & C1 & C1 C & C2. $\mathrm{C}$ & C1 & C1 & C1 & c1 & $\mathrm{C2} 2$ & C1. & $\mathrm{Cl}$ & C1. & C1 & C1 & $\mathrm{col}$ & C1 & C1 & C1 \\
\hline RHS -47 & & c3 & $\mathrm{C}_{2}+$ & $\mathrm{C}_{2}+$ & $\mathrm{C}_{2} \mathrm{C}$ & $\mathrm{C} 1+\mathrm{C}$ & $\mathrm{C} 2+\mathrm{C}$ & $\mathrm{C} 2+\mathrm{C}$ & $\mathrm{C} 2+\mathrm{C}$ & $\mathrm{C} 2+$ & C1 & C1 C & C2. $\mathrm{C}$ & C2 & c1 & C2. & $\mathrm{C} 2$. & C1 & C1 & c1 & C1 & C1 C & C1. c & C1 & Ct & c1 & co & C1 & c1. & C1. & $\mathrm{co}$ & C1. & $c_{1}$. & $\mathrm{co}$ & c1. & C1 & C1 \\
\hline R123 & & & C3 & $\mathrm{C} 2+$ & $\mathrm{C}_{2}$ & $\mathrm{C2}$ & $\mathrm{Cl} \mathrm{C}$ & $\mathrm{C} 2+\mathrm{C}$ & $\mathrm{C} 2+\mathrm{C}$ & $\mathrm{C2}+$ & C2. & $\mathrm{C}_{2} \mathrm{C}$ & $\mathrm{C}_{2}-\mathrm{C}$ & $\mathrm{C} 2$ & $\mathrm{C}_{2}$ & C1* & C1 & C1 & $\mathrm{C} 2+\mathrm{C}$ & c2. & C1 & C1 & c1 $c$ & C1 & C1 & C1 & $\mathrm{c1}$ & C1 & C1 & C1. & C1 & $\mathrm{co}$ & c1. & $c 0$ & C1 & C1+ & $C_{1}$ \\
\hline F48 & & & & c3 & $\mathrm{C2}+$ & $\mathrm{C} 2 \mathrm{C}$ & $\mathrm{C}_{2}+$ & $\mathrm{C} 2 \mathrm{C}$ & $\mathrm{C2}+\mathrm{C}$ & $\mathrm{C2}$ & $\mathrm{C} 2+$ & C1. & C1 & C1 & C1 & C1 & C1. & C1. & $\mathrm{C} 2+\mathrm{C}$ & C1. & C1. & C1. C & C1: C & C1 & C1 & C1 & C1. & co & C1 & C1 & C1. & $\mathrm{Cl}$ & C1. & $c 0$ & C2. & C1* & C1 \\
\hline $88-033$ & & & & & C3 & $\mathrm{C} 2 \mathrm{C}$ & $\mathrm{C} 2+\mathrm{C}$ & $\mathrm{C} 2+\mathrm{C}$ & $\mathrm{C}_{2}+\mathrm{C}$ & $\mathrm{C2}$ & $\mathrm{C} 2$ & C2. & C1 & C2 & C1 & C2. & C2. & C1. & C1. & $\mathrm{C1}$ & co & $\mathrm{CO}$ & C1 C & C1. & C1. & C1 & c1. & $c 0$ & Co & c1. & C1. & $c 0$ & C1 & $\mathrm{co}$ & C1. & C1. & C1 \\
\hline RT-23 & & & & & & c3 & $\mathrm{C} 2$ & $\mathrm{C} 2 \mathrm{C}$ & $\mathrm{C2}_{2}+\mathrm{C}$ & $\mathrm{C2}$ & C2. & C1 C & C1 & $\mathrm{C2}$ & C1 & C1 & C1. & C1. & c1. & C1- & $\mathrm{C}_{2}$ & C1 & C1 C & C1. & C1 & C2. & C1. & $\mathrm{co}$ & C1. & $\mathrm{Co}$ & $\mathrm{co}$ & C1. & C1. & $\mathrm{Cl}$ & C1 & C1. & $\mathrm{co}$ \\
\hline PS-2 & & & & & & & $\mathrm{c} 3 \mathrm{c}$ & $\mathrm{C}_{2}+\mathrm{C}$ & $\mathrm{C}_{2} \mathrm{C}$ & $\mathrm{C}_{2+}$ & C2. & C2. & $\mathrm{C} 2$ & C1 & $\mathrm{C} 2$. & C1 & C2. & C1 & C1 & $\mathrm{C}_{2}$ - & C1 & C2. & C1 C & C1 & C2. & C1 & C1. & C1- & C1. & C1 & $\mathrm{co}$ & $\mathrm{Co}$ & C1. & $\mathrm{co}$ & $\mathrm{Cl}_{2}$ & C1 & $c_{1}$ \\
\hline R144 & & & & & & & & $\mathrm{C}_{3}$ & $\mathrm{C}_{2} \mathrm{C}$ & $\mathrm{Cl}_{+}$ & $\mathrm{C}_{2}$ & $\mathrm{C} 2 \mathrm{C}$ & C2. & $\mathrm{C2}$ & $\mathrm{Cl}_{1}$ & $\mathrm{C}_{2}$. & $\mathrm{C} 2$ & C1 & $\mathrm{C2}$ & C1 & co & C1. C & C1. C & $\mathrm{C2}$. & C2. & C1 & c1 & c1. & Co & $\mathrm{CO}$ & c1. & $\mathrm{co}$ & $\mathrm{Cl}_{1}$. & $\mathrm{Co}$ & C1 & C2. & $\mathrm{Cl}_{1}$ \\
\hline R10S & & & & & & & & & $\mathrm{C}_{3}$ & $\mathrm{C2}$ & C2. & C2. C & C2. C & $\mathrm{C}_{2}$. & $\mathrm{C} 2$. & $\mathrm{C}_{2}$ & C2. & Ci C & $\mathrm{C}_{2}+$ & $\mathrm{Ct}$ & $c o$ & C1. & C1 C & C1 & C1 & c1. & c1 & C1. & c1 & C1. & c1. & C1. & $\mathrm{Co}$ & C1 & C1 & $c_{1}$ & C1. \\
\hline$R 002$ & & & & & & & & & & $\mathrm{cs}$ & $\mathrm{C} 2 \mathrm{C}$ & C2. $\mathrm{C}$ & $\mathrm{ClC}$ & C2. & c1 & $\mathrm{Cl}$ & $\mathrm{Cl}$ & C2. & $\mathrm{Cl}$ & C2. & C1 & C1. C & $\mathrm{C1} \mathrm{C}$ & $\mathrm{C2}$. & C1 & C1 & Cr. & C1. & c1. & C1. & C1. & $\mathrm{Cl}$ & C1. & $c 0$ & $\mathrm{Cl}+$ & C2. & C1. \\
\hline TE2-4 & & & & & & & & & & & C3 & $\mathrm{C} 2 \mathrm{C}$ & $\mathrm{C2}$ & $\mathrm{C} 2$ & $\mathrm{C2}$ & $\mathrm{C} 2$ & $\mathrm{C} 2$ & $\mathrm{C2}$ & $\mathrm{C2}$ & $\mathrm{C2}$ & C1 C & $\mathrm{C} 2+\mathrm{C}$ & $\mathrm{C2} \mathrm{C}$ & $\overline{C 1}$ & C2 & $\overline{\mathrm{C} 2}$ & C2. & $\overline{C 2 . c}$ & $\overline{C 1+}$ & C1 & C2. & & $\mathrm{C} 1+$ & C2. & C1 & C1. & $c 0$ \\
\hline SHC81 & & & & & & & & & & & & $\mathrm{C} 3 \mathrm{C}$ & $\mathrm{C}_{2}+\mathrm{C}$ & $\mathrm{C} 2$ & $\mathrm{C2}$ & $\mathrm{C} 2$ & $\mathrm{C} 2$ & $\mathrm{C} 2$ & $\mathrm{C} 2$ & $\mathrm{C2}$ & C2 & C2 & $\mathrm{C} 2 \mathrm{C}$ & C1 & C2 & $\mathrm{C} 2$ & C2. & C2. & C2. & $\mathrm{C} 2$. & $\mathrm{Cl}$ & C2. & $\mathrm{C} 2$. & C2. & C1 & c1 & C1. \\
\hline Al1-4 & & & & & & & & & & & & & $\mathrm{C3} \mathrm{c}$ & $\mathrm{C}_{2}+$ & $\mathrm{C2}$ & $\mathrm{C} 2$ & C2. & $C_{1}$ & $\mathrm{C2}$ & $\mathrm{C2}$ & C1 & $\mathrm{Cl} \mathrm{C}$ & C2. C & C1 C & C1. & C1 & C1 & C2. & c1. & C1. & C1 & $\mathrm{C}_{2}$. & $\mathrm{C}_{2}$ & C1. & co & C1 & $\mathrm{co}$ \\
\hline SH1-2 & & & & & & & & & & & & & & $\mathrm{Ca} \mathrm{C}$ & $\mathrm{C} 1+$ & $\mathrm{C}_{2}$ & $\mathrm{C}_{2}$ & C1 & $\mathrm{C2}$ & $\mathrm{C}_{2}$ & C2 & $\mathrm{C} 2$ & C2 C & C2. & C1 & C2 & $\mathrm{C}_{2}$ & C1 & c1. & C2. C & $\mathrm{Cl}+$ & C1 & C1 & $\mathrm{Cl}_{+}$ & C1 & C1 & C1 \\
\hline SH1.3 & & & & & & & & & & & & & & & $\cos$ & $\mathrm{C} 2$ & $\mathrm{C}_{2}$ & C1 & $\mathrm{C}_{2}$ & C1 & C2. & C1 C & C1 C & C2. & C1 & $\mathrm{C}_{2}$ & Cr. & C1. & c1. & C1. & C1 & C1. & C1 & $\mathrm{C} 2$. & C1 & c1. & C1. \\
\hline $65-L-2$ & & & & & & C3 & & & & & & & & & & $\mathrm{cs}$ & $\mathrm{C2}+\mathrm{C}$ & $\mathrm{C} 2+\mathrm{C}$ & $\mathrm{C} 2+\mathrm{C}$ & $\mathrm{C2} 2$ & C2. C & $\mathrm{C} 2+\mathrm{C}$ & $\mathrm{C} 2+\mathrm{C}$ & $\overline{\mathrm{C} 2}+\mathrm{C}$ & $\mathrm{C} 2+\mathrm{C}$ & $\mathrm{C} 2+\mathrm{C}$ & $\mathrm{C} 2+$ & $\mathrm{Cl}+$ & $\overline{C 2 . C}$ & $\overline{\mathrm{C} 1+}$ & $\mathrm{C2}$ & C1 & C1 & C1 & C1 & c1. & C1 \\
\hline $87-36-1$ & & & & & CLC & ONA & $\mathrm{AL}^{\prime \prime}$ & & & & & & & & & & $\mathrm{c} 3 \mathrm{c}$ & $\mathrm{C} 2+\mathrm{C}$ & $\mathrm{C} 2+\mathrm{C}$ & $\mathrm{C2}+$ & $\mathrm{C} 2+\mathrm{C}$ & $\mathrm{C} 2+\mathrm{C}$ & $\mathrm{C}_{2}+\mathrm{C}$ & $\mathrm{C} 2+\mathrm{C}$ & $\mathrm{C}_{2+}$ & $\mathrm{C} 2 \mathrm{C}$ & $\mathrm{C} 2+$ & $\mathrm{C}_{2+}$ & $\mathrm{C} 2$ & $\mathrm{C2}$ & $\mathrm{C2}$ & C1: & C1. & C1 & C1 & c1 & co \\
\hline $88-40-1$ & & & & & & & & & & & & & & & & & & $\mathrm{C}_{3}$ & $\mathrm{C} 2 \mathrm{C}$ & $\mathrm{C} 2+$ & $\mathrm{C}_{2} \mathrm{C}$ & $\mathrm{C} 2+\mathrm{C}$ & $\mathrm{C}_{2}+\mathrm{C}$ & $\mathrm{C} 2+\mathrm{C}$ & $\mathrm{C} 2+\mathrm{C}$ & $\mathrm{C} 2+\mathrm{C}$ & $\mathrm{C} 2+$ & $\mathrm{C} 2+$ & $\mathrm{C} 2$ & $\mathrm{C2}$ & $\mathrm{C} 2+$ & C1 & C1 & C.2. & C1 & C1. & c1 \\
\hline $89-21-4$ & & & & & $\mathrm{C} 2$ &,$+ \mathrm{C}$ & $\mathrm{C} 2$ & & & & & & & & & & & & $\mathrm{Ca} \mathrm{C}$ & $\mathrm{C} 2+$ & $\mathrm{C2}$ & $\mathrm{C2}$ & $\mathrm{C} 2 \mathrm{c}$ & $\mathrm{C} 2 \mathrm{C}$ & $\mathrm{C}_{2}+\mathrm{C}$ & $\mathrm{C} 2+\mathrm{C}$ & $\mathrm{C2}+$ & $\mathrm{C2}$ & $\mathrm{C} 2$ & $\mathrm{C2}$ & $\mathrm{C2}$ & C1 & C1 & $\mathrm{C} 1+$ & C1. & C1. & $\mathrm{co}$ \\
\hline C.96 & & & & & 'STR & RON & NG" & & & & & & & & & & & & & $\mathrm{Cs}$ & C2. C & $\mathrm{C} 2+\mathrm{C}$ & $\mathrm{Cl}+\mathrm{C}$ & $\mathrm{C2} \mathrm{C}$ & $\mathrm{C} 1+\mathrm{C}$ & $\mathrm{C} 2$. & $\mathrm{C2}$ & C2. & $\mathrm{C} 2+\mathrm{C}$ & $\mathrm{CZ}_{2}$. & $\mathrm{C2}_{2}$ & C1 & $\mathrm{Cl}$ & $\mathrm{C1}$ & C1. & $\mathrm{Co}$ & $\mathrm{Co}$ \\
\hline DR-G02 & & & & & & & & & & & & & & & & & & & & & c3 c & $\mathrm{C} 2+\mathrm{C}$ & $\mathrm{C} 2 \mathrm{C}$ & $\mathrm{C} 2 \mathrm{C}$ & $\mathrm{C} 2+\mathrm{C}$ & & $\mathrm{C1+}$ & $\overline{\mathrm{C} 2+}$ & $\mathrm{C1}$ & $\mathrm{C2} 2+$ & $\mathrm{C} 2$. & C2. & $\mathrm{C2}-\mathrm{C}$ & $\mathrm{Cl}+$ & C1 & $\mathrm{Co}$ & $\mathrm{co}$ \\
\hline$w-22$ & & & & 2 & $\mathrm{C} 1$ &,$+ \mathrm{C}$ & C1, & C1. & & & & & & & & & & & & & & $\mathrm{ca} \mathrm{C}$ & $\mathrm{C}_{2}+\mathrm{C}$ & $\mathrm{C} 2+\mathrm{C}$ & $\mathrm{C} 2+\mathrm{C}$ & $\mathrm{C} 2+\mathrm{C}$ & $\mathrm{C} 2+$ & $\mathrm{C} 2+\mathrm{C}$ & $\mathrm{C} 2+$ & C2. & $\mathrm{C2}$ & C1 & C1 & $\mathrm{Cl}$ & co & c1. & C1. \\
\hline H-13 & & & & & BRID & DGII & ING' & & & & & & & & & & & & & & & & $\mathrm{C} 3 \mathrm{C}$ & $\mathrm{C} 2$ & $\mathrm{C} 2 \mathrm{C}$ & $\mathrm{C} 2+$ & $\mathrm{C} 2$ & C1 & C1 & $\mathrm{C} 1$ & $\mathrm{C1}$ & & & $\mathrm{C} 1+$ & C1 & co & C1. \\
\hline $87-24-4 A$ & & & & & & & & & & & & & & & & & & & & & & & & Ca c & $\mathrm{C}_{2}+\mathrm{C}$ & $\mathrm{C} 2$ & $\mathrm{C} 2$ & $\mathrm{C2}$ & $\mathrm{C} 2$ & $\mathrm{C} 2 \mathrm{C}$ & $\mathrm{Cl}+$ & C1 & $c_{1}$ & $\mathrm{ct}$ & C1 & c1. & C1. \\
\hline$H \cdot 3-77$ & & & & & & $\mathrm{CO}$ & & & & & & & & & & & & & & & & & & & $\cos \mathrm{c}$ & $\mathrm{C2}+$ & $\mathrm{C2}$ & $\mathrm{C} 2+\mathrm{C}$ & $\mathrm{C}_{2}+\mathrm{C}$ & $\mathrm{C}_{2}+$ & $\mathrm{C2}$ & C1 & C2. & $\mathrm{C}_{1}$ & co & co & $\mathrm{co}$ \\
\hline R9 & & & & NO & RE & EAC & TIO & ON" & & & & & & & & & & & & & & & & & & $\mathrm{csc}$ & $\mathrm{C} 2 ._{+}$ & & $\mathrm{C2}+$ & $\mathrm{C}_{2} \mathrm{C}$ & $\mathrm{Cl}+$ & $\mathrm{Cl}+$ & C1 & C1. & $c 0$ & c1. & C1 \\
\hline R164 & & & & & & & & & & & & & & & & & & & & & & & & & & & $\mathrm{cs}$ & $\mathrm{C} 2+\mathrm{C}$ & & $\mathrm{C}_{2}+\mathrm{C}$ & $\mathrm{C2}$. & C1 & C1 & $\mathrm{Cl}$ & C1 & Co & $\mathrm{Co}$ \\
\hline 48R & & & & & & & & & & & & & & & & & & & & & & & & & & & & c3 & $\mathrm{C2}$ & $\mathrm{C} 2+\mathrm{C}$ & $\mathrm{C} 2+$ & C1. & C1 & $\mathrm{CO}$ & $c 0$ & $c 0$ & $c 0$ \\
\hline G4 & & & & & & & & & & & & & & & & & & & & & & & & & & & & & $\mathrm{C3}$ & C3 & $\mathrm{C2}$ & c1. & C1. & C1. & co & co & C1. \\
\hline G8 & & & & & & & & & & & & & & & & & & & & & & & & & & & & & & $\mathrm{C3}$ & $\mathrm{C2}$ & C1. & c1. & C1. & C1. & $\mathrm{co}$ & $\mathrm{co}$ \\
\hline RGR38 & & & & & & & & & & & & & & & & & & & & & & & & & & & & & & & $\mathrm{ca}$ & $\mathrm{Cl}$ & C1 & C1. & C1. & c1. & $\mathrm{co}$ \\
\hline $758 \mathrm{C}$ & & & & & & & & & & & & & & & & & & & & & & & & & & & & & & & & cs & C2 & $\mathrm{C1}$ & $c 0$ & $\mathrm{co}$ & C1. \\
\hline $\begin{array}{c}777 \text { RIPS } \\
\text { SI -2 }\end{array}$ & & & & & & & & & & & & & & & & & & & & & & & & & & & & & & & & & c3 & $\mathrm{C} 2$ & Co & co & $\mathrm{co}$ \\
\hline 221 & & & & & & & & & & & & & & & & & & & & & & & & & & & & & & & & & & $\mathrm{c} 3$ & C1. & C1. & $\mathrm{Co}$ \\
\hline H5-307 & & & & & & & & & & & & & & & & & & & & & & & & & & & & & & & & & & & $\mathrm{C3}$ & $\mathrm{C2} \cdot$ & $\mathrm{C} 2+$ \\
\hline $\mathrm{H} 17-4$ & & & & & & & & & & & & & & & & & & & & & & & & & & & & & & & & & & & & c3 & $\mathrm{C} 2+$ \\
\hline LB17.3.2 & & & & & & & & & & & & & & & & & & & & & & & & & & & & & & & & & & & & & cos \\
\hline
\end{tabular}

Fig. 1. Anastomosis reactions between paired isolates in all combinations of 37 isolates representing seven subsets of Rhizoctonia solani anastomosis group-2 (AG-2). 
Development and testing of subset-specific primer pairs. Subset-specific primer pairs were designed for each of the seven subsets of AG-2 listed in Figure 1. In addition, a primer pair that was specific to all isolates of AG-2-2 (including IIIB, IV, and LP) was also designed. Primer pair designations, sequences, annealing temperatures, and product sizes are listed in Table 3. Except for annealing temperature, amplification programs for all primer pairs were identical: initial denaturation at $94^{\circ} \mathrm{C}$ for 2 min was followed by 30 cycles of: (i) denaturation at $94^{\circ} \mathrm{C}$ for $40 \mathrm{~s}$, (ii) annealing at the temperature specific for the primer pair (Table 3) for $1 \mathrm{~min}$, and (iii) extension at $72^{\circ} \mathrm{C}$ for $1 \mathrm{~min}$. A final extension at $72^{\circ} \mathrm{C}$ for 5 min followed completion of the 30 cycles.

The specificity of each primer pair was assessed in amplification reactions against the 37 isolates listed in Table 1 as well as 74 additional isolates representing the subsets of AG-2 (60 isolates), most other $R$. solani AG (11 isolates), binucleate Rhizoctonia (two isolates), and one $R$. solani isolate of unknown identity. Purified genomic DNA from isolates of the various subsets of AG-2 produced only the expected product when treated with the appropriate primer pair. All isolates of the three subsets of -2-2 (IIIB, IV, and LP) produced the expected product when amplified with primer pair P22. Isolates of $R$. solani representing AG-1, -3, -4, -5, -6, -7, $-8,-9,-10,-11,-12$, and the unknown AG produced no product in response of the primer pairs specific to subsets of AG-2. The two binucleate Rhizoctonia also produced no product. The complete list of isolates and reactions to subset specific primers is available from D. E. Carling or S. Kuninaga upon request.

\section{DISCUSSION}

The anastomosis-based system of grouping isolates of $R$. solani, though occasionally imprecise, is beneficial because it enables us to better understand this large and highly heterogeneous species. Use of hyphal anastomosis reactions has led to the characterization of 14 anastomosis groups in $R$. solani, AG-1 through AG-13 and AG-BI $(3-5,23,24)$. Based on data presented in this article, we propose that AG-BI be redefined as a subset of AG-2, designated AG-2 BI, reducing the number of AGs to 13.

AGs are composed of isolates that anastomose with one another, although some isolates, via the relatively weak bridging anastomosis reaction, may show an affinity for two or more AGs. Strong (C2) anastomosis reactions indicate AG membership, whereas bridging reactions (C2- or less) may or may not indicate AG membership. Bridging reactions are sometimes observed between obviously discrete AGs (i.e., AG-3 and AG-2) but, as our data show, also occur between isolates of the same AG.

In addition to characterizing isolates to AG, hyphal anastomosis reactions have sometimes been used for characterizing subsets of AGs (24). Our data show that anastomosis reaction is unreliable and of little value for the purpose of subset identification within AG-2. Instead, one or more criteria other than anastomosis reaction are needed to identify AG-2 subsets.

The concept of bridging was originally defined in terms of fusion frequency (15) and, at that time, indicated an anastomosis relationship between isolates from different AGs. The anastomosis relationship of the bridging group, AG-BI, to certain isolates of AG-2, -3 , and - 6 was recognized; nevertheless, because of other differences (15), AG-BI was described as a discrete AG. Isolates of AG-BI anastomosed strongly with each other but also established the weaker bridging anastomosis reactions with certain isolates of AG-2, -3 , and -6 (15). The concept of bridging has changed from one describing the anastomosis relationships between AG-BI and certain other AGs to one that also includes description of relationships among subsets of AG-2. This evolution in definition, along with evidence presented herein, indicates that AG-BI is more appropriately classified as AG-2 BI, one of the many related subsets of AG-2. With inclusion of AG-BI in AG-2, the most prominent remaining examples of inter-AG bridging

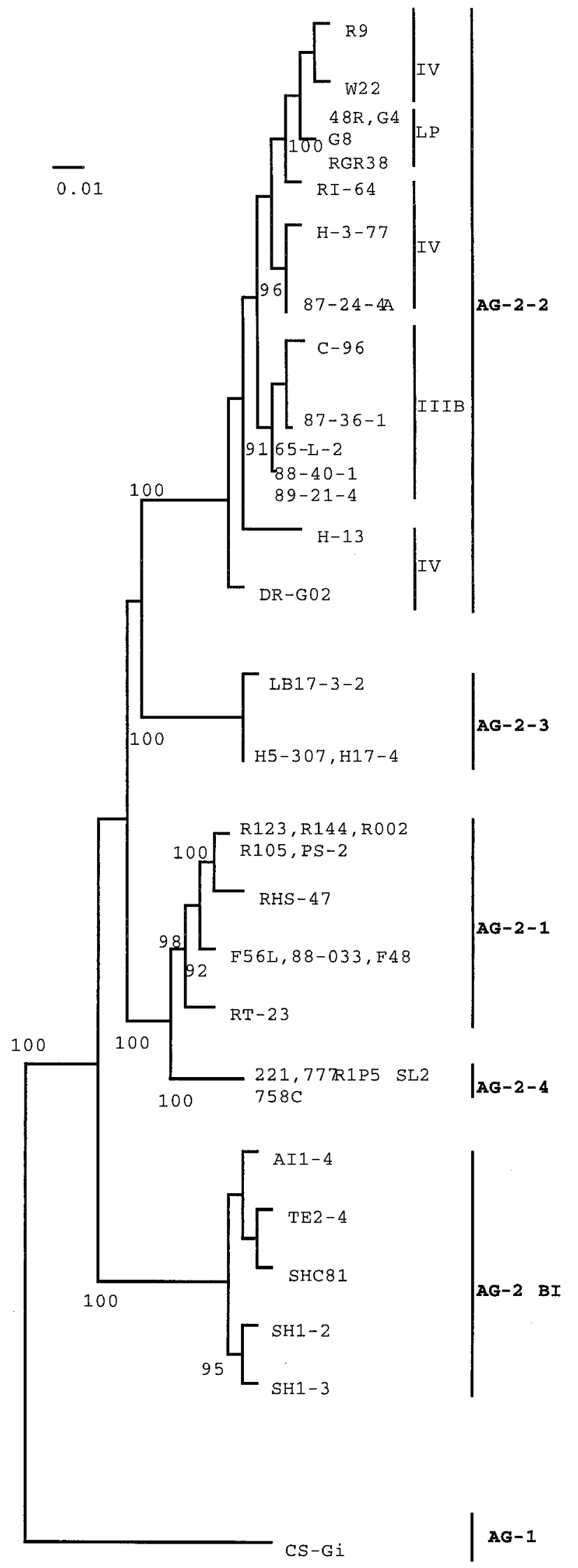

Fig. 2. A neighbor-joining tree illustrating estimates of phylogenetic relationships of AG-2-1, -2 BI, -2-2 IIIB, -2-2 IV, -2-2 LP, -2-3, and -2-4 of Rhizoctonia solani. Distances were determined by Kimura's two-parameter model (10). The bar indicates one base change per 100 nucleotide positions. Numbers alongside branches represent the percentage of congruent clusters in 1,000 bootstrap trials when the values were greater than $90 \%$. 
include AG-2-AG-3 bridging and AG-2-AG-8 bridging (3). Additional studies designed to answer questions regarding the anastomosis relationships between AG-2, AG-3, and AG-8 are underway.

As long as AG affinity remains a characterization criterion for $R$. solani, care must be taken to insure that AG labels are applied accurately. We were reminded of this need when confirming the anastomosis affinity of isolates acquired for use in this study. Three isolates acquired from the ATCC (10163, an R. solani but AG unknown; 56049, a binucleate Rhizoctonia; and 58120, a binucleate Rhizoctonia) labeled as AG-2 in the ATCC database actually are members of the groups indicated above. These isolates were not included in the final set.

Sometimes isolates misidentified according to AG do end up in published studies. For example, Boysen et al (2) determined ITS sequences of isolates described as hypovirulent AG-4s (34) that now, based on comparison of their ITS data (2) with ITS sequence data from additional isolates of AG-4 and binucleate Rhizoctonia (S. Kuninaga, unpublished data), are known to be binucleate Rhizoctonia. Not surprisingly, the binucleate isolates clustered separately from the genuine AG-4 isolates in the Boysen report (2). In another study, Liu and Sinclair (17), using DNA restriction and isozyme polymorphisms, characterized isolates of AG-3 (11, 36) from tobacco as $2 \mathrm{E}$, a unique subset of AG-2. Again, it is not surprising that isolates from one AG would cluster separately from isolates of another AG. These and other examples provide useful reminders of the need to confirm AG identity.

Other important techniques, in addition to anastomosis, ITS sequencing, and virulence, have been used to characterize subsets of AG-2. Liu and Sinclair (17), using isozyme polymorphisms and
DNA restriction analyses, characterized subsets A, B, C, D, and E; generally corresponding to -2-1, -2-2 IIIB, -2-2 IV, -2-2 LP (turf grass), and a population from tobacco (actually isolates of AG-3) $(11,36)$, respectively. Stevens-Johnk and Jones $(35)$, using cellular fatty acid composition, also characterized subsets of -2-2. Using some of the same isolates as Liu and Sinclair (17), they differentiated isolates of -2-2 IIIB from populations collected from sugar beet (-2-2 IV), St. Augustine grass (-2-2 LP), and corn (35). Stevens-Johnk and Jones described their "corn" population as closely related to -2-2 IIIB, an identification we confirmed by determining the ITS sequences of isolates from their "corn" collection (data not shown). In other studies, pectic zymogram patterns (19) have been used to separate AG-2 into five subsets (ZG3, ZG4, ZG5, ZG6, and ZG10). Members of each of those ZG will anastomose with one or more of the subsets of AG-2 included in this research. These as well as other techniques can be effectively used to separate AG-2 subsets but all could not be included in this study. Application of these and other subset defining-techniques to the set of isolates evaluated in this study will permit more critical evaluation of AG-2 subsets and subset defining criteria.

The subdivision of AG-2 based on one or combinations of criteria $(1,6,12,24,33)$ has enhanced understanding of AG-2 by grouping similar isolates. The best known subsets of AG-2 are -2-1, -2-2 IIIB, -2-2 IV, -2-2 LP, and -2-3. Each has been characterized according to many criteria and each, by one or more methods, is distinguishable from the others. To this list of AG-2 subsets we now propose the designation $-2 \mathrm{BI}$ for the group formerly known as AG-BI (15). Our data show it anastomosing extensively with all subsets of AG-2 and anastomosing strongly with -2-1, -2-2 IIIB,

TABLE 2. Observed damage to germinating seedlings of cauliflower, lettuce, and sugar beet caused by isolates representing 10 AG or AG subsets of Rhizoctonia solani ${ }^{\text {a }}$

\begin{tabular}{|c|c|c|c|c|c|c|c|c|c|}
\hline \multirow[b]{2}{*}{ Host } & \multirow[b]{2}{*}{$\mathrm{AG}^{\mathrm{b}}$} & \multirow[b]{2}{*}{ Subgroup } & \multirow[b]{2}{*}{ No. of isolates } & \multicolumn{3}{|c|}{3 days after inoculation ${ }^{c}$} & \multicolumn{3}{|c|}{8 days after inoculation ${ }^{\mathrm{c}}$} \\
\hline & & & & None & Medium & Dead & None & Medium & Dead \\
\hline Cauliflower & $\ldots$ & & $\ldots$ & 18 & 0 & 0 & 18 & 0 & 0 \\
\hline Cauliflower & 1 & IC & 1 & 0 & 0 & 18 & 0 & 0 & 18 \\
\hline Cauliflower & 2 & BI & 5 & 15 & 3 & 0 & 6 & 12 & 0 \\
\hline Cauliflower & 2 & $2 \mathrm{IIIB}$ & 5 & 0 & 18 & 0 & 0 & 3 & 15 \\
\hline Cauliflower & 2 & $2 \mathrm{IV}$ & 7 & 10 & 8 & 0 & 0 & 3 & 15 \\
\hline Cauliflower & 3 & PT & 1 & 18 & 0 & 0 & 6 & 12 & 0 \\
\hline Cauliflower & 4 & HGI & 1 & 0 & 0 & 18 & 0 & 0 & 18 \\
\hline Lettuce & $\ldots$ & $\ldots$ & $\ldots$ & 17 & 0 & 0 & 18 & 0 & 0 \\
\hline Lettuce & 1 & IC & 1 & 5 & 9 & 0 & 0 & 18 & 0 \\
\hline Lettuce & 2 & 1 & 10 & 18 & 0 & 0 & 8 & 10 & 0 \\
\hline Lettuce & 2 & BI & 5 & 15 & 3 & 0 & 11 & 7 & 0 \\
\hline Lettuce & 3 & PT & 1 & 12 & 4 & 0 & 14 & 4 & 0 \\
\hline Lettuce & 4 & HGI & 1 & 0 & 2 & 16 & 0 & 1 & 17 \\
\hline Sugar beet & $\ldots$ & $\ldots$ & $\ldots$ & 15 & 0 & 0 & 18 & 0 & 0 \\
\hline Sugar beet & 1 & IC & 1 & 0 & 13 & 0 & 0 & 6 & 8 \\
\hline Sugar beet & 2 & 1 & 10 & 7 & 8 & 0 & 4 & 6 & 6 \\
\hline Sugar beet & 2 & BI & 5 & 14 & 1 & 0 & 10 & 5 & 0 \\
\hline Sugar beet & 2 & 2 IIIB & 5 & 8 & 4 & 0 & 0 & 3 & 15 \\
\hline Sugar beet & 2 & $2 \mathrm{IV}$ & 7 & 5 & 8 & 0 & 1 & 2 & 12 \\
\hline Sugar beet & 2 & $2 \mathrm{LP}$ & 4 & 14 & 0 & 0 & 12 & 2 & 1 \\
\hline Sugar beet & 2 & 3 & 3 & 15 & 0 & 0 & 6 & 9 & 2 \\
\hline Sugar beet & 2 & 4 & 3 & 8 & 8 & 0 & 0 & 16 & 0 \\
\hline Sugar beet & 3 & PT & 1 & 12 & 2 & 0 & 11 & 7 & 0 \\
\hline Sugar beet & 4 & HGI & 1 & 0 & 4 & 11 & 0 & 0 & 18 \\
\hline
\end{tabular}

${ }^{a}$ Experiment run twice with similar results. Data shown are from the second run.

b $\mathrm{AG}=$ anastomosis group.

${ }^{\mathrm{c}}$ Medium = medium damage; tissue discoloration and necrosis starting at hypocotyl and sometimes extending down the root or up the stem. Number indicates the number of seedlings exhibiting each symptom. 
and -2-2 IV. Anastomosis reactions of -2 BI with the major subsets of AG-2 (-2-1 and -2-2) are so strong that, in our opinion, the basic definition of $\mathrm{AG}(3)$ requires its inclusion in $\mathrm{AG}-2$.

We also report a heretofore unknown population, designated AG-2-4, of isolates collected from carrot or corn. AG-2-4 is another unique and highly virulent subset of AG-2 and is believed to be common in vegetable fields in southern Georgia (D. R. Sumner, personal communication). Isolates of -2-4 were very aggressive pathogens, killing lettuce, radish, and cauliflower under the environmental conditions used in this study. Its anastomosis characteristics and rDNA-ITS sequences distinguish it from all other subsets of AG-2; however, its anastomosis reactions with all other subsets of AG-2 is so weak that in time -2-4 may be found to qualify as an independent AG. AG-2-4 also bridges with some tester isolates of AG-10 (data not shown), an AG not previously known to bridge with any other AG. The virulence of -2-4 coupled with its unique ITS sequences suggests it will be identified more frequently in the future.

Virulence levels and host range are important and useful characteristics to know about isolates of $R$. solani. Sometimes these characteristics have been used to define groups or subgroups. For example, even prior to grouping by anastomosis reaction, the membership of what is now known as AG-3 had been approximately defined on the basis of virulence on potato. More recently, AG-3 was divided into two subsets based on virulence and host range: one that attacks only potato and one that attacks only tobacco $(11,36)$. More often, virulence and host range are not particularly valuable group-defining criteria, and our data illustrate that this is true for AG-2. Under the environmental conditions used in this experiment, conditions highly favorable to the pathogen, certain subsets of AG-2, most notably -2-1, -2-2 IIIB, -2-2 IV, and $-2-4$, each heavily damaged at least two of the four host species. Other subsets, including -2-2 LP, -2-3, and -2 BI, tended to cause less damage. From these data, one may be able to place an isolate into a "high" or "minimal" damage group; generally, however, one may not be able to place an isolate into its specific subset. Not all AG-2 subsets attack the four plant species listed (i.e., -2-3 attacks soybean and -2-2 LP attacks turf grass); therefore, inclusion of additional hosts very likely would enhance the power of this host range and virulence test. However, the variable results that often can be expected from virulence tests make them poor choices for defining groups. Virulence and host range do remain useful when comparing isolates or populations. For example AG-2t, a subset of -2-1, cannot be separated from other -2-1 isolates based on anastomosis reactions and certain other criteria but can be separated from other -2-1 isolates based on virulence on tulip (31).
The ITS sequencing portion of our research parallels research summarized in recent papers by Salazar et al. $(29,30)$, although we did observe some noteworthy differences in results. First, their positioning of AG-BI is inconsistent with ours. An investigation of this point, including sequencing of isolates of ATCC 76132 (Salazar's BIRO1) from two sources (ATCC and the original isolate from S. Kuninaga's collection) revealed that BIRO1 (GenBank Accession No. U57885) does not possess the ITS sequence of ATCC 76132 (DDBJ Accession No. AB054873). Furthermore, the reported sequence of BIRO1 is dissimilar from all isolates of AG-BI but similar to sequences of $-2-1$ isolates. Second, the sequence data of Salazar et al. (29) for isolates of -2-2 LP is highly variable among isolates, whereas our -2-2 LP sequences are nearly identical among isolates. Isolates of -2-2 LP are described as very similar to one another (8) and our sequence, virulence, and anastomosis data confirm this similarity.

Although the Salazar et al. $(29,30)$ data on sequence and length of ITS regions frequently do not agree with ours, their distance analysis shows, as does ours, the discreetness of all established subsets of AG-2, including subsets of the subset -2-2 (29). They also indicate, and we agree, that anastomosis reactions appear not to correlate directly with phylogenetic relationships implied by ITS sequences. In addition, they report that $-2-1$ is heterogeneous and composed of three subsets, including (i) cruciferous -2-1, (ii) Japanese -2-1, and (iii) Dutch -2t (30). Although not clearly evident from anastomosis data, we also observed heterogeneity within -2-1 based on virulence and ITS sequence differences. However, our subsets of -2-1 based on ITS sequence were constituted differently: (i) Japanese -2-1 plus Dutch -2t, (ii) Alaskan and Australian -2-1, and (iii) Italian Nt isolates (data not shown). That -2-1 is heterogeneous seems clear. What is less obvious at this time is how or if to articulate these differences.

As has been shown in AG-3 (11), subset-specific primers can provide a subjective and relatively simple way to apply rDNA-ITS sequence differences to AG subset identification. The groupspecific primers designed for subsets of AG-2 performed without fail when tested on the 37 isolates central to this study. They also worked without fail when tested against 60 additional isolates representing subsets of AG-2, 11 isolates representing the other $\mathrm{AG}$, and 3 isolates incorrectly labeled as AG-2. However, because of the well known heterogeneity within AG-2, a final evaluation of these group-specific primers will follow additional testing with many isolates from a broad selection of hosts, environments, and geographical locations.

$R$. solani AG-2 is a highly heterogeneous assemblage of isolates. Assessment of similarities and differences among these isolates sometimes adds confusion rather than clarification be-

TABLE 3. Sequences, annealing temperatures, and product sizes of primer pairs specific to subsets of Rhizoctonia solani anastomosis group (AG)-2

\begin{tabular}{|c|c|c|c|c|}
\hline Primer pair designation & Specificity & Sequences $^{\mathrm{a}}$ & Annealing temperature $\left({ }^{\circ} \mathrm{C}\right)$ & Product sizes $(b p)^{b}$ \\
\hline $\mathrm{P} 21$ & AG-2-1 & $\begin{array}{l}\text { 5'-CAAAGGCAAT(A/G)GGTTATTGGAC-3' } \\
\text { 5'-CCTGATTTGAGATCAGATCATAAAG-3' }\end{array}$ & 60 & 480 \\
\hline P2-BI & AG-2 BI & $\begin{array}{l}\text { 5'-GAATGAAG(C/T)AATC(A/G)GGGAACC-3' } \\
\text { 5'-GATCATAAAAATATTGTCCAAGCT-3' }\end{array}$ & 55 & 510 \\
\hline P22 & AG-2-2 & $\begin{array}{l}\text { 5'-GGCTC(C/T)(A/G)TTA(A/G)TTTGGAG-3' } \\
\text { 5'-TGTGAAGCTGCAAGAACC-3' }\end{array}$ & 55 & 400 \\
\hline P22-IIIB & AG-2-2 IIIB & $\begin{array}{l}5^{\prime} \text {-AGGCAGAG(A/G)CATGGATGGGAG-3' } \\
\text { 5'-ACCTTGGCCA(A/C)CCTTTTTATC-3' }^{\prime}\end{array}$ & 62 & 500 \\
\hline P22-LP & AG-2-2 LP & $\begin{array}{l}5^{\prime} \text {-AGGCAGAGAAACATGGATGGGC- }{ }^{\prime} \\
5^{\prime} \text {-CCTCCAATACCAAAGTGAAACCAAATC-3' }\end{array}$ & 62 & 400 \\
\hline $\mathrm{P} 23$ & AG-2-3 & $\begin{array}{l}5^{\prime} \text {-GTAGCTGGCTCATCGTTCTT-3' } \\
5^{\prime} \text {-CATTTCCCTTGGCCACCTTTG-3' }\end{array}$ & 60 & 530 \\
\hline $\mathrm{P} 24$ & AG-2-4 & $\begin{array}{l}\text { 5'-GGGGAATTTATTTGTTGTTTTTTGTAATAG-3' } \\
\text { 5'-CAATGGACTATTAGAAGCA-3' }^{\prime}\end{array}$ & 55 & 440 \\
\hline
\end{tabular}

\footnotetext{
a The first listed primer in each pair is the "forward" primer and the second is the "reverse" primer.

${ }^{b}$ Product begins in the internal transcribed spacer (ITS) 1 region at the $3^{\prime}$ end of the forward primer and ends in the ITS 2 region at the 5 ' end of the reverse primer.
} 
cause of the subjective nature of many assessment criteria. Virulence and host range, though characteristics of central importance to plant pathologists, often are subjective and of little value as grouping criteria. Hyphal anastomosis, though a valuable groupdefining criterion, can be a subjective and at times difficult technique to master. rDNA-ITS sequencing offers an objective supplemental evaluation that, when used along with hyphal anastomosis reaction, should eliminate erroneous characterization of isolates within AG-2. rDNA-ITS sequences, in the form of subset-specific primer pairs, should simplify even further the process of subset identification within AG-2.

\section{LITERATURE CITED}

1. Adams, G. C., Jr. 1988. Thanatephorus cucumeris (Rhizoctonia solani): A species complex of wide host range. Adv. Plant Pathol. 6:535-552.

2. Boysen, M., Borja, M., del Moral, C., Salazar, O., and Rubio, V. 1996. Identification of stain level of Rhizoctonia solani AG-4 isolates by direct sequence of asymmetric PCR products of the ITS regions. Curr. Genet. 29:174-181.

3. Carling, D. E. 1996. Grouping in Rhizoctonia solani by hyphal anastomosis. Pages 37-47 in: Rhizoctonia Species: Taxonomy, Molecular Biology, Ecology, Pathology, and Disease Control. B. Sneh, S. JabajiHare, S. Neate, and G. Dijst, eds. Kluwer Academic Publishers, Dordrecht, The Netherlands.

4. Carling, D. E., Baird, R. E., Kuninaga, S., and Gitaitis, R. D. 1999. Characterization of anastomosis group (AG)-13 of Rhizoctonia solani. (Abstr.) Phytopathology 89(suppl.):S11.

5. Carling, D. E., Pope, E. J., Brainard, K. A., and Carter, D. A. 1999. Characterization of mycorrhizal isolates of Rhizoctonia solani from an orchid, including AG-12, a new anastomosis group. Phytopathology 89: 942-946.

6. Cubeta, M. A., and Vilgalys, R. 1997. Population biology of the Rhizoctonia solani complex. Phytopathology 87:480-484.

7. Higgins, D. G., Bleasby, A. J., and Fuchs, R. 1992. Clustal V: Improved software for multiple sequence alignment. Comput. Appl. Biosci. 8:189191.

8. Hyakumachi, M., Mushika, T., Ogiso, Y., Toda, T., Kageyama, K., and Tsuge, T. 1998. Characterization of a new cultural type (LP) of Rhizoctonia solani AG-2-2 isolated from warm-season turfgrasses, and its genetic differentiation from other cultural types. Plant Pathol. 47:1-9.

9. Kanematsu, S., and Naito, S. 1995. Genetic characterization of Rhizoctonia solani AG-2-3 by analyzing restriction fragment length polymorphisms of nuclear ribosomal DNA internal transcribed spacers. Ann. Phytopathol. Soc. Jpn. 61:18-21.

10. Kimura, M. 1980. A simple method for estimating evolutionary rates of base substitutions through comparative studies of nucleotide sequences. J. Mol. Evol. 16:111-120.

11. Kuninaga, S., Carling, D. E., Takeuchi, T., and Yokosawa, R. 2000. Comparison of rDNA-ITS sequences between potato and tobacco strains in Rhizoctonia solani AG-3. J. Gen. Plant Pathol. 66:2-11.

12. Kuninaga, S., Natsuaki, T., Takeuchi, T., and Yokosawa, R. 1997. Sequence variation of the rDNA ITS regions within and between anastomosis groups in Rhizoctonia solani. Curr. Genet. 32:237-243.

13. Kuninaga, S., Nicoletti, R., Lahoz, E., and Naito, S. 2000. Ascription of Nt-isolates of Rhizoctonia solani to anastomosis group 2-1 (AG-2-1) on account of rDNA-ITS sequence similarity. J. Plant Pathol. 82:61-64.

14. Kuninaga, S., and Yokosawa, R. 1992. Genetic diversity of Fusarium oxysporum $\mathrm{f}$. sp. lycopersici in restriction fragment length polymorphisms of mitochondrial DNA. Trans. Mycol. Soc. Jpn. 33:449-459.

15. Kuninaga, S., Yokosawa, R., and Ogoshi, A. 1979. Some properties of anastomosis groups 6 and BI in Rhizoctonia solani Kühn. Ann. Phytopathol. Soc. Jpn. 45:207-214.

16. Lipman, D. J., and Peason, W. R. 1985. Rapid and sensitive protein similarity searches. Science $227: 1435-1441$.

17. Liu, Z., and Sinclair, J. B. 1992. Genetic diversity of Rhizoctonia solani anastomosis group 2. Phytopathology 82:778-787.

18. MacNish, G. C., Carling, D. E., and Brainard, K. A. 1996. Relationship of microscopic vegetative reactions in Rhizoctonia solani and the occurrence of vegetatively compatible populations (VCP) in AG-8. Mycol. Res. 100:61-68.

19. MacNish, G. C., Carling, D. E., Sweetingham, M. W., and Brainard, K. A. 1994. Anastomosis group (AG) affinity of pectic isozyme (zymogram) groups (ZG) of Rhizoctonia solani from the Western Australian cereal-belt. Mycol. Res. 98:1369-1375.

20. Moore, R. T. 1987. The genera of Rhizoctonia-like fungi: Ascorhizoctonia, Ceratorhiza gen. nov., Epulorhiza gen. nov., Moniliopsis, and Rhizoctonia. Mycotaxon 29:91-99.

21. Naito, S., and Kanematsu, S. 1994. Characterization and pathogenicity of a new anastomosis subgroup AG-2-3 of Rhizoctonia solani Kühn isolated from leaves of soybean. Ann. Phytopathol. Soc. Jpn. 60:681-690.

22. Nicoletti, R., Lahoz, E., Kanematsu, S., Naito, S., and Contillo, R. 1999. Characterization of Rhizoctonia solani isolates from tobacco fields related to anastomosis groups 2-1 and BI (AG 2-1 and AG BI). J. Phytopathol. 147:71-77.

23. Ogoshi, A. 1976. Studies on the grouping of Rhizoctonia solani Kühn with hyphal anastomosis, and on the perfect stage of groups. Bull. Natl. Inst. Agric. Sci. Ser. C No. 3. Natl. Inst. Agric. Sci. Tokyo Jpn. 30:1-63.

24. Ogoshi, A. 1987. Ecology and pathogenicity of anastomosis and intraspecific groups of Rhizoctonia solani Kühn. Annu. Rev. Phytopathol. $25: 125-143$

25. Ogoshi, A., and Ui, T. 1979. Specificity in vitamin requirement among anastomosis groups of Rhizoctonia solani Kühn. Ann. Phytopathol. Soc. Jpn. 45:45-53.

26. Parmeter, J. R., Sherwood, M. W., and Platt, W. D. 1969. Anastomosis grouping among isolates of Thanatephorus cucumeris. Phytopathology 59:1270-1278

27. Rehner, S. A., and Samuels, G. J. 1994. Taxonomy and phylogeny of Gliocladium analyzed from nuclear large subunit ribosomal DNA sequence. Mycol. Res. 98:625-634.

28. Saitou, N., and Nei, M. 1987. The neighbor-joining method: A new method for reconstructing phylogenetic trees. Mol. Biol. Evol. 4:406-425.

29. Salazar, O., Julian, M. C., Hyakumachi, M., and Rubio, V. 2000. Phylogenetic grouping of cultural types of Rhizoctonia solani AG-2-2 based on ribosomal ITS sequences. Mycologia 92:505-509.

30. Salazar, O., Schneider, J. H. M., Julian, M. C., Keijer, J., and Rubio, V. 1999. Phylogenetic subgrouping of Rhizoctonia solani AG-2 isolates based on ribosomal ITS sequences. Mycologia 91:459-467.

31. Schneider, J. H. M., Schilder, M. T., and Dijst, G. 1997. Characterization of Rhizoctonia solani AG-2 causing bare patch in field grown tulips in the Netherlands. Eur. J. Plant Pathol. 103:265-279.

32. Sherwood, R. T. 1969. Morphology and physiology in four anastomosis groups of Thanatephorus cucumeris. Phytopathology 59:1924-1929.

33. Sneh, B., Burpee, L., and Ogoshi, A. 1991. Identification of Rhizoctonia species. The American Phytopathological Society Press, St. Paul, MN.

34. Sneh, B., Zeidan, M., Ichielevich-Auster, M., Barash, I., and Koltin, Y. 1986. Increased growth responses induced by a nonpathogenic Rhizoctonia solani. Can. J. Bot. 64:2372-2378.

35. Stevens-Johnk, J., and Jones, R. K. 1993. Differentiation of populations of AG-2-2 of Rhizoctonia solani by analysis of cellular fatty acids. Phytopathology 83:278-283.

36. Stevens-Johnk, J., Jones, R. K., Shew, H. D., and Carling, D. E. 1993. Characterization of populations of Rhizoctonia solani AG-3 from potato and tobacco. Phytopathology 83:854-858.

37. Takeuchi, T., Sawada, H., Tanaka, F., and Matsuda, I. 1996. Phylogenetic analysis of Streptomyces spp. causing potato scab based on 16S rRNA sequence. Int. J. Syst. Bacteriol. 46:476-479.

38. Watanabe, B., and Matsuda, A. 1966. Studies on the grouping of Rhizoctonia solani Kühn pathogenic on upland crops. Bull. Appl. Exp. 7:1-131.

39. White, T. J., Bruns, T., Lee, S., and Taylor, J. 1990. Amplification and direct sequencing of fungal ribosomal RNA genes for phylogenetics. Pages 315-322 in: PCR Protocols. A Guide to Methods and Applications. M. A. Innis, D. H. Gelfand, J. J. Sninsky, and T. J. White, eds. Academic Press, San Diego, CA. 